\title{
I Text English to Everyone: Links between Second-Language Texting and Academic Proficiency
}

\author{
Michelle A. McSweeney \\ Center for Spatial Research, Graduate School of Architecture, Planning and Preservation, Columbia University, \\ 1172 Amsterdam Avenue, New York, NY 10027, USA; mam2518@columbia.edu; Tel.: +1-347-314-0072
}

Academic Editors: Sonia Rocca and Bryan Smith

Received: 21 February 2017; Accepted: 21 June 2017; Published: 27 June 2017

\begin{abstract}
This article reports on research investigating the relationship between text messaging and academic literacy among Spanish-dominant emergent bilingual young adults in New York City (acquiring English). Through assessments of academic language and analysis of a corpus of 44,597 text messages, this study found that emergent bilinguals who send more messages in English and choose English for the settings on their mobile phones tend to have higher academic English skills. This study also found that the English messages they send are lexically less dense than the Spanish messages, illustrating that students use a narrower vocabulary when texting in their second language. This finding is explored in light of previous research that has found that using social media in the target language can help students develop fluency and intercultural competence skills, but not always vocabulary. The results are discussed in terms of the tendency for texters to text monolingually and other affordances and constraints of smart phone use in digitally supporting second language acquisition.
\end{abstract}

Keywords: text messaging; computer assisted language learning; SMS; computer mediated communication; second language acquisition; literacy

\section{Introduction}

In recent years, smart phone ownership has grown globally, with smart phones accounting for $80 \%$ of mobile phone sales [1,2]. In the United States (where the present study is based), over $92 \%$ of adults age 18-29 have access to a smartphone and use it to access the internet at least once a day [3,4]. Correspondingly, it seems that language learning applications (apps) have proliferated, with both free and paid apps promising to help students learn a wide variety of languages. Some offer vocabulary or grammar drills, others prioritize learning through repetition. At their core, though, they all operate on the same principle, namely that if users have immediate access to a learning tool, they will practice more, and if they practice more, they will learn the language. With this model, language learning can be done while waiting for a bus, standing in a line, or even while doing something else entirely. While these apps are beneficial [5,6], both second language learners and Second Language Acquisition (SLA) researchers know that in order to communicate in a language, one must interact with others through that language [7]. The question then becomes: in what ways do language learners already use the target language on their phones?

This paper argues that smart phones are more than a tool for instructed SLA, and can provide an unique opportunity for naturalistic practice of a target language in a digital environment. Smart phones emerged as tools for interpersonal communication, be that one-to-one (messaging), or one-to-many (social media), and at their core, they are communication devices. The most frequently used features across all types of mobile phones are messaging-type applications such as WhatsApp (WhatsApp Inc., Mountain View, CA, USA), Google Chat (Google Inc., Mountain View, CA, USA), 
or WeChat (Tencent Holdings Limited, Shenzhen, China). Through these, billions of messages are sent every day [8], connecting people who are both geographically near and far. The significance of the rise of messaging cannot be overstated as it means that individuals are writing many of their social interactions.

Texting is different from speaking in a few key ways: messages can be reflected upon and edited during the writing process, and authors can reference them afterwards. This presents a unique situation for the language learner as she can produce a form in the target language and reflect on and edit it before sending; she can use autocorrect to correct grammar or spelling, and she can look up a word to increase her vocabulary in the target language. However, this also means that if a language learner chooses to text in the target language, she may be practicing a conversational rather than academic form of the language.

Using digital tools for language learning is nothing new, though; in the second language classroom, computer assisted language learning has been commonplace for many years. In a comprehensive survey of the literature reaching back to 1970, Grgurovic, Chapelle, and Shelley found that computer-supported pedagogy yields a small, but statistically significant, positive effect on student learning outcomes (over analogue approaches) [9]. Researchers consistently find that computer mediated environments prioritize the types of linguistic interactions that foster second language learning, including collaboration [10], focusing on communication [11], and interaction [12]. Early on, researchers and educators were excited about the potential for text-based interaction to support language learning $[10,13,14]$ as it allows learners to "freeze a single frame and focus attention on it" such that "Students' own interactions can now become a basis for epistemic engagement" [10] (p. 472) (as we shall see, students in this study are highly sensitive to the ability to focus on a single message, both for their own reflection and the possibility that their messages will be reflected on by others).

This technological shift marks a drastic change from either spoken communication or analogue written communication because messaging platforms (such as instant messaging, chat rooms, and text messaging, etc.) allow learners to revise before sending their messages and engage in near-synchronous conversations. In a detailed survey of the literature on second language acquisition in online contexts, Chapelle concluded that "online communication can include both the focus on meaning that occurs in social conversation and the focus on form that can push learners' linguistic competence" [13] (p. 381). Research, before and since, has confirmed her conclusions, highlighting the potential of online contexts as language learning platforms.

Since the advent of Web 2.0 (social) technologies, researchers, educators, and students alike have sought to use the social capabilities for language learning [15]. Research in this vein has looked at Facebook (Facebook, Inc., Menlo Park, CA, USA) [16-18], language learning chat rooms [19] and instant messaging [20], amongst others [2]. In separate studies, Dizon [16] and Mitchell [18] found that using Facebook in the target language (English in both instances) supports SLA. Mitchell found that joining Facebook and engaging with the platform encouraged students to use English even when they joined for other reasons; Facebook gave students a place and purpose for practicing English in a naturalistic setting [18]. To better understand these effects, Dizon conducted a controlled experiment to determine if using Facebook for writing assignments could have an effect on language learning. He gave writing assignments to Facebook users (experimental group) and non-users (control group) and assessed students on fluency, lexical richness, and grammatical accuracy before and after the experiment. He found that Facebook users improved in writing fluency over the control group, but there was no effect on measures of lexical richness or grammatical accuracy [16].

The Facebook studies begin to address a common dichotomy in language learning research-the distinction between naturalistic and artificial settings. Over the years, research on Computer Assisted Language Learning has incorporated more studies of language use in naturalistic settings. Whereas many early studies focused on educational games and platforms, more recent work has turned to language use on mobile phones, which are already a part of students' daily lives. To this end, text messaging is unique because for many people, it is considered an intimate communication form to 
communicate with those we are socially close with such as friends and family [21]. In a survey of Arabic and Thai speaking students both studying abroad and at home, Jarvis and Krashen found that most students use their first language when messaging, though they use both their first language and English (a second language for all students) for various digital interactions [22]. They found that the fewest students (67\%) use English when messaging, and the most students use English when playing games (96\%) [22]. As of 2017, English is widely regarded as a necessary language to learn to engage with content on the internet [23]. However, though English is a global language, it is not necessarily the preferred language of interpersonal or intimate communication.

\subsection{Texting and Academic Literacy}

Because of the differences between conversational and academic language forms, some educators, parents, and journalists fear that text messaging and instant messaging could negatively affect academic literacy skills through exposure to "incorrect" (non-prescriptive) forms [24,25]. Some worry that students will use colloquial language in their academic work $[26,27]$ or that they will not be able to distinguish when they should use formal varieties rather than "Txt" varieties [28] ("Txt" refers to the language form commonly found on digital platforms, and its characteristic features such as unconventional spelling, abbreviations, emoticons, and emojis [29]). There is little evidence for these concerns as it seems that most young adults are able to separate academic and texting language and know when to use each [30]. Yet many young adults still believe that texting will negatively affect their literacy skills [31]. In a study of 80 college students, Drouin and Davis found that students who use Txt and those who do not perform similarly on standardized measures of academic literacy. However, more than half of the students in their study believe that using Txt would negatively affect their academic literacy skills [31]. Their beliefs are not unfounded, however, as research has produced mixed results on the relationship between various dimensions of Txt/texting and academic literacy skills.

Studies focused on the relationship between text messaging and literacy have produced mixed results. Some have found that textism awareness and use is positively correlated with academic literacy skills [32-34]. Others have found little or no correlation between the two [31], and still others have found a negative correlation between textism use and literacy skills [35,36]. De Jonge and Kemp found that these discrepancies may at least partially be due to age differences [37]. In both a review of the literature and an independent study, they found that textism use correlated positively with literacy skills for children and negatively for adults [37].

Initially, it may be surprising that age matters in this way. However, research into this question suggests that rather than age per se, the difference between the effects may be due to differences in how deeply integrated literacy skills are into the daily practices of children and adults [38]. Since most children have not fully integrated or automated their literacy skills before owning a mobile phone, they may benefit from practicing writing and playing with language by using textisms and creative devices. On the other hand, many adults' literacy skills were fully formed before they owned a phone, making those skills less susceptible to influence from future practice [38-40].

Drouin and Driver further explore this topic by categorizing the types of textisms used (such as stylizations versus omitted punctuation) [41]. This, they argue, may give greater insights into the relationship between texting and literacy skills. They propose a distinction between "positive" and "negative" textism categories. For them, positive textisms are non-prescriptive forms that require linguistic awareness (such as $t k+$ to represent te quiero más or 'I love you more'), and exhibit a level of linguistic playfulness or creativity. Negative textisms, on the other hand, do not require linguistic awareness, but rather may reflect a lack of awareness or attention (such as omitting punctuation or capitalization). In their study of the text messages from 183 college undergraduates, they find that positive textisms are associated with higher literacy levels, and negative with lower literacy levels [40], illustrating that not all texting and textisms are the same. Given that the students who showed greater linguistic attention in their texting (through positive textisms) demonstrated higher 
literacy skills, one might predict that English learners who choose to text in English would also demonstrate higher literacy skills since they are also showing greater linguistic attention through the use of a non-dominant language.

To date, there have been few studies focused specifically on the texting patterns of bilinguals learning a second language. Those that do address second language acquisition and texting are largely focused on the use of colloquial forms in academic writing [42,43]. So any predictions made based on the results of studies with monolingual populations should be treated with caution. It is obvious that the language skills of an emergent bilingual young adult are not necessarily the same as a monolingual child or adult. The one study that does explicitly address the relationship between naturalistic texting behavior and academic literacy acquisition is mostly concerned with the intrusion of textisms into academic writing rather than overall literacy skills [43]. While this is certainly an important question, it is more concerned with how students learn registers, rather than how text messaging is related to the development of academic literacy or vice versa.

The issue becomes more complicated when we take into account the predictive spelling and autocorrect associated with the keyboard's dictionary. Focusing on these features, in a study of the texting behavior of first-year undergraduates, Ouellette and Michaud determine that as texting has become more standardized, frequency or fluency of text messaging has little relationship to academic language skills [44]. This begs the question of what happens when the autocorrect is used not to simply correct inattentive texting, but as a key element of feeling comfortable texting (in a given language). While the presence of autocorrect can make textisms more difficult to produce (since it often requires overriding the keyboard), does the presence of modern texting technology still neutralize the relationship between texting and literacy? While this question cannot be efficiently addressed through corpus study, the relationship between texting and literacy remains a poorly understood one for emergent bilinguals acquiring a second language.

\subsection{Lexical Diversity}

Thinking about text messaging as a platform where English Language Learners could practice their linguistic skills is only valid insofar as students are utilizing it to practice new vocabulary and language forms. Lower proficiency learners often rely on a limited range of words to express themselves when writing in the second language, and that having a limited vocabulary makes writing in the second language more difficult [45-47]. Yet vocabulary is consistently shown to be a strong indicator of the quality of writing [45,48]. In developing vocabulary, using the words in writing or speaking is critically important in committing that word to memory $[49,50]$.

Yet because text messaging is a colloquial language form, the range of vocabulary that students need to communicate is narrower than in an academic setting [51]. If a student were to text the way they write for class, it would be socially inappropriate. However, even in a colloquial setting, students can use a large number of different words in order to express themselves, and in a learner environment, lexical diversity helps to illustrate the quality of writing across genres [45,52].

Logistically, however, the lexical diversity of any given language sample is difficult to calculate computationally. In this case, lexical density is used as a proxy for lexical diversity. Lexical density is highly correlated with lexical diversity across language forms [53]. Where lexical diversity is a measure of the variety of words used in a language sample, lexical density is a measurement of how many lexical words are used in a language sample relative to the entire sample. Lexical words are open-class words such as nouns, verbs and adjectives. Function words are closed-class words such as prepositions, articles and auxiliaries. Vocabulary acquisition in both the first and second language is often measured by the number of lexical words an individual knows and uses as opposed to the function words [54]. In the end, this is a way to separate the vocabulary that a student uses from the way that they structure their sentences.

Finally, metrics of lexical diversity and vocabulary have been used extensively to understand student writing $[45,46,48]$, and even the relationship between students' written proficiency and their 
oral proficiency [55]. However, this line of inquiry is yet to be extended into texting research. Since texting is a social platform rather than an academic one, there is a socially-imposed cap on the range of vocabulary texters should use, as it would be very strange to text as if one were writing an academic essay. Whether language learners are at or near that threshold is likely due to the proficiency level of the individual learner, though the relationship between lexical diversity in the dominant versus non-dominant language is yet to be determined.

\subsection{Social Networks}

Since text messaging is an inherently social communication form, one might wonder how learners' social worlds are constructed. It might be that students simply do not have anyone to text with in English, or they have few opportunities to use English meaningfully within their social networks. There are, of course, many theories within SLA that specifically treat this question in depth. Some ask if interaction is necessary for language acquisition [7,56,57], others focus more on motivation [58] or social investment [59]. What they all have in common is that to use a language, a learner must have someone to use it with. In a setting such as New York City, a Spanish dominant English learner could spend their life mostly with Spanish speakers or mostly with English speakers. This binary setting is complicated by the high rate of bilingualism in New York City, so a better question is what is the primary language of communication rather than what language(s) do people speak. Addressing this dimension of learners' lives helps to contextualize the texting data by situating the language of text messaging within participants' larger social lives.

Building on this research, this study seeks to understand the relationship between texting in English and academic literacy skills, the lexical diversity of those messages, and the social networks learners are embedded in. Using a corpus of text messages, multimodal literacy assessments, and surveys, this study seeks to approach these questions using a combination of naturalistic and experimental data.

\section{Materials and Methods}

\section{Research Questions}

1. Is there a relationship between the percentage of messages a student sends in English (their second language) and their academic literacy skills in English?

2. Are the messages students send in English as lexically diverse as the messages they send in Spanish (their first language)?

3. Do students who have more English conversation partners have higher academic English language skills?

\subsection{Participants}

Forty-two participants age 18 to 21 were enrolled in the study; fifteen students took all of the assessments and chose to donate their text messages. All participants are Spanish-dominant in social settings and are developing both Spanish and English academic proficiencies. All participants were born in Latin America (the Dominican Republic, Mexico, Guatemala, and Ecuador), and arrived in the United States during the typical high school years (age 13-18), and all participants own a mobile phone. Participants were recruited based on their enrollment in a dual language (Spanish/English) High School Equivalency (HSE) program in New York City.

This population was chosen for three reasons. First, they are English Learners (ELs), and there has not been any corpus-based research into the text messaging patterns of ELs. Second, to broaden the work being done on text messaging to include adults without a college education; the vast majority of work on adult text messaging is based on undergraduate students, who are a comparatively highly educated population. By creating a corpus of messages written by students without college experience, the available research is diversified to create a more complete picture of the language used on text 
messaging. Finally, Spanish-dominant English Learners were selected because Spanish is the most commonly spoken language after English in the United States [60]. Because of this, there are entire HSE classes at different levels, allowing for more robust comparisons.

\subsection{Survey}

Participants completed a comprehensive background survey where they provided demographic information, and detailed their linguistic and educational experiences, as well as data about their text messaging practices. The survey consisted of thirty-nine questions in four sections (Demographics, Academic Experiences, Linguistic Background, and Phone Use), and was administered in English with a Spanish translation (since this was an English language class, students were encouraged to complete all in-class exercises in English).

One section of the survey consisted of a grid with groups of people listed (i.e., grandparents, parents, siblings, friends, etc.). Students answered the following questions by filling out the grid:

1. For each person, what language or languages do you mostly use?

2. For each person, what language do you mostly use to send messages (texts, chats, tweets, etc.)? If you often mix languages, please list both languages.

3. For each person, how do you like to communicate with them? Please choose your favorite 3 methods.

Students were instructed to think about the groups collectively, "so, when talking to your siblings, what language(s) do you use"? Responses to these questions were tabulated to determine what groups of people in their lives the students use English, Spanish, or Spanglish (a combination of Spanish and English).

\subsection{Academic Assessment Materials}

Participants' academic language skills were assessed in three different modalities: written, aural, and digital. The variety of tasks was intended to minimize the effect of any given modality and to develop a holistic picture of students' literacy skills. To assess written comprehension, participants took the English Literacy Evaluation for Newcomer Students with Interrupted Formal Education (LENS). This assessment was designed for students who have had non-traditional schooling experiences. In the LENS, participants read a short passage and answered multiple choice reading comprehension questions. The LENS was created by the SLA Lab at the Graduate Center at The City University of New York and commissioned by the New York City (NYC) Department of Education. The results were assessed based on a rubric and aligned to grade level (maximum possible grade level $=10$ th grade, maximum grade level achieved $=9$ th grade) .

To assess aural comprehension of academic language, participants took the aural comprehension component of the Academic Communication in English for Long-Term English Learners (ACE). Students watched two academically oriented videos and answered written questions. In this task, students were told they could write their answers in English or Spanish, though the videos are in English. This task is assessed based on content, not language form. The ACE was also written by the SLA Lab and commissioned by the NYC Department of Education. The results were assessed based on a rubric and aligned to grade level (maximum possible grade level $=9$ th grade, maximum grade level achieved $=9$ th grade) .

To assess academic language skills in a digital format, students participated in a vocabulary guessing game on Google Chat. Students received a word list and were paired with a student with a different list. Their teachers assisted in the pairing to ensure that students of comparable abilities worked together. Students were then instructed to describe the words on the list so the other person could guess it. Once one person guessed a word, they moved on to the next word, taking turns in the respective roles. Vocabulary words came from the 6-9th grade Common Core State Standards and had appeared on vocabulary lists the teachers used that semester. Students were instructed to use either Spanish or English 
to describe the words although the words were in English. The team who guessed the most words received a small prize. Students were scored based on how many words they knew and could define ( maximum possible grade level $=9$ th grade, maximum grade level achieved $=9$ th grade) .

Finally, students' scores from the English language component of the Test of Adult Basic Education (TABE CLAS-E) were considered. This is a speaking, reading, writing, and listening test. Students take the TABE upon entering the Pathways to Graduation Program to determine overall academic preparation. The scores were aligned to grade level (maximum possible grade level $=9$ th grade, maximum grade level achieved $=7$ th grade) .

The scores from these four assessments were averaged to create an overall academic language proficiency level aligned to the American grade system for each student.

\subsection{Text Messages}

Participants donated the text message histories from their phones. After cleaning the messages, removing automated responses, and hand masking them to remove any identifying information, there were 44,597 messages with nearly 1.2 million words.

\subsection{Procedure}

Data were collected over a six-week period during which researchers met with participants twice a week. Each week, students had one session of data collection and one workshop on communication for academic and professional purposes. All assessments were administered in a classroom setting during their regularly scheduled English Language Arts Class. On the first day, students were introduced to the study, signed the consent form, and took the survey. On each assessment day, the teacher and both researchers were in the room to explain and administer the tests. On the last day, students donated their text messages. To donate their messages, students plugged their phones into the researchers' computers, entered their passcode, and allowed the researchers to make a copy of their text message history. To ensure that there is no identifying information in the messages, the messages were first anonymized computationally. Then, two independent researchers read each message and removed any names, numbers, addresses, descriptions, or references to anything that could identify the sender. The entire corpus is available in the Bilingual Youth Texts (BYTs) Corpus at https://byts.commons.gc.cuny.edu/.

\subsection{Message Processing}

Once the messages were cleaned and normalized, they were tagged with the language they were written in. To determine language for each message, 9000 messages (approximately 20\%) were randomly selected and hand tagged by a Spanish/English Bilingual research assistant. Messages were tagged as one of four categories: English, Spanish, Bilingual, and Other. Those written completely in English or completely in Spanish were tagged as such. "Bilingual" messages are those written in both Spanish and English, and include both instances of borrowing (inserting one word from another language) and code switching (starting a message in one language and finishing it in another). "Other" messages are those that consist only of emojis, numbers, addresses, $o k, l o l$, links, and images since these items are language agnostic. This set of 9000 messages was used as a training set, and the language of the remaining messages was determined with the Naïve Bayes supervised classification model in Python's Natural Language Toolkit (http:/ / www.nltk.org/). The result was 89\% accuracy for language identification.

The overwhelming majority of the messages are monolingual—written in either English (25\%) or Spanish (57\%), with only $1 \%$ involving code-switching, or a mixture of both languages. This may be surprising given that participants are bilingual and live in New York City, where mixing Spanish and English is a well-established language practice [61-63]. However, mobile phone technology, in its default setting, encourages monolingual behavior. All participants except for one rely on autocorrect to assist them in writing their messages. Many students felt that it helps them "sound smarter". While 
they had no problem switching keyboards and therefore switching languages between messages, within one message, they had to override the autocorrect feature which is both time consuming and, as one participant described, "annoying". The one student who disabled the autocorrect from his phone explained "I can't write like myself, I sound fake, like in class". Most of the instances of code switching were produced by this student.

To calculate lexical density, the corpus was normalized to remove capitalization, punctuation, and emojis since they are not relevant for this study (see Example 2). Commonly respelled words (i.e., $w$ for ' $w$ ith' and other common abbreviations) were treated as the same word since the objective of this study is to investigate lexical diversity and different spellings of the same word are the same word (counting types rather than tokens). Interjections were removed since they represent sounds rather than words. This step was performed for both English and Spanish words, and reduced the number of words by $12 \%$.

Then, a copy of the corpus was made and the stop words were removed (see Example 1). Stop words are all of the function words in a language. While there is no definitive list of stop words, the list built in to the Natural Language Toolkit for Python is widely used by linguists and language researchers. Given the popularity of this list and the ease of using it with other language analysis processes, it was used for the present study. The English and Spanish messages were separated and the respective stop words were removed from each language. Since lexical density is highly sensitive to corpus length, the same number of words from each participant (in each language) were considered. Since every participant donated at least 250 words (stop words included, emojis and other non-lexical items omitted), the first 250 words from each participant's corpus were considered. For many participants, this is approximately 50 messages each. On average, messages were 5.1 words long $(S D=8.6)$. Very long messages (greater than 25 words) were excluded from the study as their function was very different from the rest of the corpus (such as a confrontation or complaint). There were 456 very long messages (approximately 1\%). There were, however, many more single word messages $(8848$, or almost $20 \%$ ). These messages were overwhelmingly either just a punctuation mark, an emoji, or a reference to laughter ( $h a h a, j a j a, l o l$, etc.). In the message language classification, out of context, these types of messages were typically classified as "Other" and therefore are not considered here. Lexical density was then calculated by dividing the number of lexical words by the total number of normalized words.

\section{Example 1.}

Original: Because we didn't have much space and the rent was toooo expensive!

Normalized: because we did not have much space and the rent was too expensive

Lexical-only: much space rent expensive.

\section{Results}

The results from the academic assessments show that students perform at an approximately 5.5 $(S D=1.7)$ grade level in academic English, though they are enrolled in courses at the 9th to 12th grade level. This degree of academic under-preparedness is similar to other groups of students such as SIFE (Students with Interrupted Formal Education). Even though participants in this study are not classified by the Department of Education as SIFE (SIFE are defined as having a documented gap of at least two years in their education [64]). So, while many participants in this study reported having a gap in their education of two years or longer, it was rarely officially documented, they share many characteristics of SIFE. Most importantly, SIFE students are typically academically underprepared in their first language. The lack of academic proficiency in their first language makes developing academic language and content mastery in their second language even more challenging [37]. The classrooms in this study use Spanish to supplement instruction when necessary, but the explicit goal is English proficiency rather than Bilingual proficiency. The average score for each assessment is shown in Table 1. 
Table 1. Academic Results.

\begin{tabular}{ccc}
\hline Assessment & $\begin{array}{c}\text { Average } \\
\text { Score }\end{array}$ & $\begin{array}{c}\text { Standard } \\
\text { Deviation }\end{array}$ \\
\hline English Literacy Evaluation for Newcomer Students with Interrupted Formal Education (LENS) & 5.90 & 1.99 \\
Academic Communication in English for Long-Term English Learners (ACE) & 5.20 & 1.64 \\
Chatting Game & 5.69 & 1.99 \\
Test of Adult Basic Education (TABE) & 5.20 \\
Average & 5.47 \\
\hline
\end{tabular}

Each participant's average score on the academic assessments was correlated with the percentage of text messages they sent that were written in English to determine if there was a relationship between academic proficiency in English and amount of English used in text messaging. These results should be treated with caution as the number of participants was so low (15). The results show a positive correlation between the percentage of English-only text messages and overall English academic proficiency $r(14)=0.78, p<0.01$.

To better understand what those text messages look like and how they may be related to English proficiency, the relationship between lexical density and percentage of messages sent in English or Spanish was considered. The results show a negative correlation between lexical density and percent English $r(14)=-0.45, p<0.05$, indicating that the students who send the most English messages also use the smallest range of vocabulary. So, while the students with the highest proficiency in academic English tend to write in English more often, the range of vocabulary they use is narrower than students who use more Spanish messages.

Finally, to better understand what domains of students' lives are conducted in each language, students estimated how many people they communicate with primarily in Spanish, English, or a mixture of both languages. The purpose of this question was to determine what areas of their life are conducted in English rather than the actual amount of Spanish, English, or Spanglish they use. On average, students reported that they use only English with $24.5 \%(n=19, S D=0.394)$ of the groups of people in their life. Teachers and bosses accounted for the majority of these individuals, with friends and significant others making up the remainder. Figure 1 illustrates the responses to this question. Students reported that they primarily used Spanish with siblings, parents, and grandparents, that they mixed languages with friends and significant others, and they used English with teachers and bosses. There is a clear trend here to use Spanish with family members (siblings, parents, and grandparents), echoing previous work that finds that the language of respect at home among Spanish-speaking families in the United States is usually Spanish, whereas the language of respect at school and work is usually English [38].

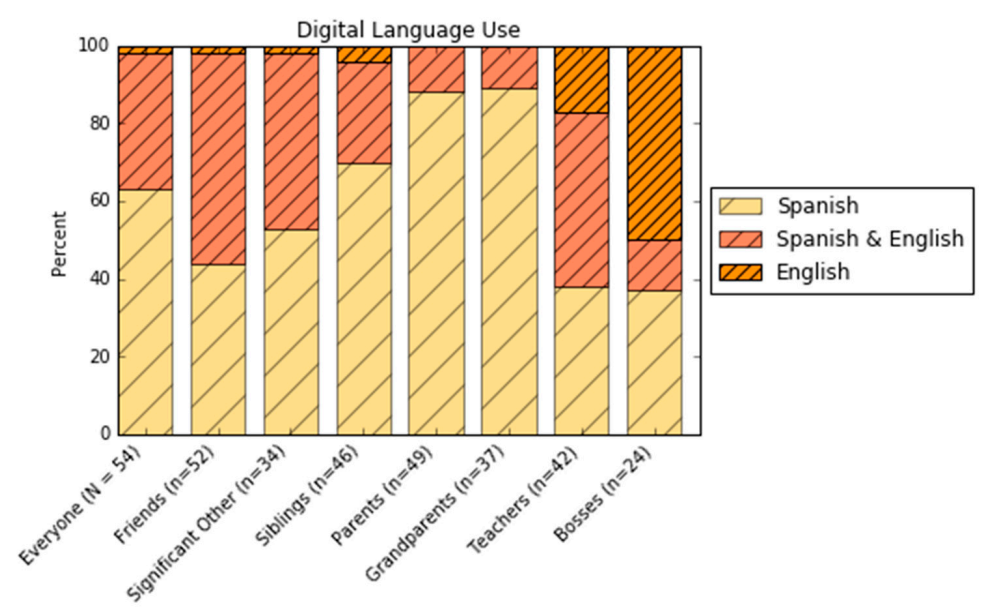

Figure 1. Language of communication on digital platforms between participants and groups of people in their lives, where $n$ is the number of respondents who reported communicating digitally with people in each category. 
The Pearson correlation for the percent of English speaker groups in participants' lives and their academic literacy skills was also calculated. The results show that students who report communicating with the most people only in English is positively correlated with academic English proficiency $r(19)=0.59, p<0.01$.

Overall, there is a positive correlation between students' academic English skills, the percent of messages they send in English, and the number of groups of people in their life who they speak English with. Initially, it may seem that if a student has more English speakers in their life, they would necessarily send more English messages. This does not necessarily follow. For example, no student had more than $50 \%$ English speakers in their life, though six students sent more than $50 \%$ of their text messages in English. Therefore, some students choose to send English messages to other Bilinguals or they text with the English speakers disproportionately. Regardless of what the reason is, this illustrates that these two correlations are not necessarily linked, though it is clear that both are positively correlated with academic English ability.

Finally, and importantly, the survey results showed that students who sent more than half of their messages in English also set the meta-language for their phone into English. All other students set the meta-language of their phone to Spanish. This means that in order to interact with their phone, they had to use English. All of these students except for one performed above a 7th grade academic English level, and all of these students participated in all three activities (the survey, academic assessments, and message donation) and had the best attendance records overall. It could be that students who are more competent in English are able to set their phone into English or students who set their phone into English are more motivated, or a combination of factors. Regardless of the reason, the effect is that in order to use their phone, they had to use English.

\section{Limitations}

The primary limitation of this study is that only fifteen individuals participated in both the academic assessments and the text message donation. This study is part of a larger investigation into the academic, social, and texting literacy skills of bilingual young adults; forty-two individuals participated in at least two activities in the larger study, yet only fifteen donated their text messaging history and took at least three academic assessments. The choice to work with HSE students was both intentional and resulted in very high attrition. There are many reasons students enroll in HSE Programs; for example, a student may have aged out of traditional high school without graduating, dropped out of high school and wanted to return, or started traditional high school too late and was not able to accumulate enough credits to graduate. Students in this study enrolled in HSE for each of these reasons and more. Because they are adults, when they enroll in HSE classes, they are not mandated to attend every class. Because of this, as well as the work and family pressures many students face, attrition in the study was very high. At the end of the study only twenty participants who began the study were still attending school; there was a 30\% loss after Spring Break. This is not unique to this study as attrition is high in HSE-type programs across the United States [39,40]. Finally, the data for this study were collected over the course of six weeks, which resulted in many students both dropping out of and joining the study between the first day and the last. Future studies should be conducted over a shorter period of time to reduce attrition and late additions.

A second limitation is that little is known about the participants' academic knowledge of Spanish. The Spanish language version of LENS was administered during the study, but only two students who took the Spanish LENS also donated their text messages. With more information about their performance on academic measures of Spanish, it would be possible to determine how first language literacy is related to both second language literacy and text messaging in both the first and second languages. 


\section{Discussion}

This study sought to investigate the relationship between texting in a second language and academic literacy by investigating the volume of messages sent in English compared with academic literacy in English, the lexical density of those messages, and the language of the social networks students are embedded in. Through a corpus-based analysis, this study found that students who text more in English tend to have higher English academic skills. However, English text messages tend to have a lower lexical density than Spanish ones. Finally, students who have more English speaking groups in their life (i.e., employers, friends, significant others, etc.) also have higher English academic literacy skills.

There are at least two ways to interpret the positive correlation between message language choice and academic literacy skill. First, it could be that that the student who has higher English literacy skills may have more confidence in texting in English and therefore be more willing and able to do so. It could also be that more practice texting in English reinforces English literacy acquisition leading to higher English literacy scores. Closer examination of the survey results may add more to the discussion. When students set up their phone, they have to make a choice about which language it will be in. This feature can be changed later through the settings, but at some point, it is a choice. It should come as no surprise then that the students who exhibited the highest levels of academic literacy also set their phones in English. Second, when students are texting with other bilinguals, they have a choice about which language(s) to use. This choice is, of course, very nuanced and complicated and is deeply tied both to the message they wish to convey and the identity they wish to construct. Given these caveats, it should be noted that the students who sent the most English language messages sent a disproportionate number of messages in English as compared to the percent of English monolinguals in their social networks.

These two decision points suggest that motivation may be an important factor in student acquisition of academic English. So, while there is a positive correlation between text message language choice and academic English literacy and between percent of English speakers in one's social network and academic English literacy, the presence of these factors in a student's life may be due to an unmeasured factor such as motivation [58], investment [59], or something else entirely. The students who intentionally set the language of their digital world in English may be making a more integrated commitment to learning English, and may be doing so because of their own desire and motivation rather than any external factors. Finally, while the causality of the relationship cannot be determined, the finding that students with higher academic literacy skills also sent more messages in English could simply be indicative of their overall linguistic skills.

Just as Drouin and Driver found that positive textisms were correlated with higher academic literacy skills and therefore potentially indicative of overall greater linguistic awareness [41], using English could be indicative of greater overall linguistic awareness in English. Whereas for Drouin and Driver, positive textisms consisted of linguistically creative forms [41], for these students positive textisms may be English language forms. For this to be true, participants would have to be extending themselves linguistically to gain any benefits from texting. Since English is a non-dominant language for all students in the present study, texting in English requires a higher degree of attention than texting in Spanish. Even though participants often rely on autocorrect or the dictionary associated with the keyboard, when they change the keyboard to English, they have made a choice to text in their non-dominant language.

Yet, the lexical diversity of students' English text messages on a whole was lower than their Spanish ones. This may be because to communicate socially, students do not necessarily have to develop an advanced vocabulary. Just as Dizon found in his study of Facebook use [16], it does not seem that students in this study are necessarily increasingly their productive vocabulary by texting in English. Rather, they are using a small set of words for very many purposes. Dizon's finding that fluency was positively affected by Facebook use, but lexical richness and grammatical accuracy were not, may help explain the negative correlation between lexical density and English use, as practicing 
English on text messaging would not be predicted to enhance vocabulary skills, though it would be expected to help students develop fluency.

When participants were asked what they do when they do not understand a word or a message, they said that they first use an online translation service (Google Translate (Google Inc., Mountain View, CA, USA) was the favorite) and if the answer is not suitable, they then turn to an online dictionary such as Urban Dictionary (http:/ /www.urbandictionary.com/). Students also reported that they sometimes use Google Translate to write messages. When asked if they ever have to look up a word they have looked up before, almost all of the students replied that they frequently have to do this until it "sticks". This echoes almost all research on second language vocabulary acquisition, which finds that students have to use a word and often have to do it multiple times before it is acquired $[46,49,50]$.

Similar to other platforms, the ability to reflect on messages is a strength of text messaging [13], even if it is for fear of judgement. To this end, one student was particularly sensitive to the fact that any message she sends could be "screenshot" (a picture could be taken of the conversation on the screen) and then sent to her interlocutor's friends. Because of this, she double checks her messages when she is writing in English. This echoes Warschauer's observation that computer mediated platforms allow students to use their own messages, their own production, for reflection and epistemic engagement, a process which is like to reinforce language learning [20]. This student said that this has helped her English because she is always thinking about the way she sounds when she is texting. Her concerns about being judged for her language practices were echoed by all participants as they felt that having all their conversations in writing sets them up for judgement in a way that speaking does not. In addition to screenshots, students were concerned that they would be considered "dumb" because of their way of writing. It is difficult to say if this is because they are writing in a second language or due to their education level or if many young adults feel this way.

Finally, it was initially surprising that though students are all able to communicate verbally in Spanish and English and frequently use what is often referred to as Spanglish, almost all of the messages were written in either Spanish or English, rarely Spanglish. As mentioned, students relied heavily on autocorrect to help them write in both languages, and it can be technically challenging to start a sentence in one language and finish it in the other. However, for at least one student, texting monolingually was an unacceptable compromise even if it meant he would text faster and misspell fewer words. From a language learning perspective, where the goal is a monolingual standard, this may be beneficial as students are encouraged by the technology to keep the languages separate and achieve a monolingual target. However, it cannot be overlooked that the effect is that in this highly social communication platform, students cannot draw on their full linguistic repertoire. This may have contributed to the lower lexical density for the English messages as it means that students were relying on only part of their vocabulary knowledge, and for many, it is the less developed part. For this group of students, their texting practices differ from their speaking and writing practices because of the constraints of the technology.

These differences may also speak to the differences in their social groups. Students in this study were asked what language they usually use to communicate with various groups in their life. From observation in the classroom and discussion with their teachers, their academic life is in Spanglish though every single student reported using English in their academic life. This speaks to the fact that the perception of what language is being used may be different from what students actually use. However, on the phone, students mostly have to choose between Spanish and English, meaning that no matter what language they are texting in, if they are a Spanglish speaker, the parallels to how they speak are weaker than they would be for a monolingual Spanish or English speaker.

In conclusion, the participants in this study are the first generation to need literacy in order to communicate socially. This has had a dramatic impact on the ways that people communicate, and provided a new found motivation to develop literacy skills. While those skills do not need to be academic in nature, the results from this study show that texting in a second language is positively correlated with higher levels of academic proficiency. In some ways, the phone is an ideal platform 
for the learner because it is social and therefore prioritizes naturalistic language, but the technology prioritizes a monolingual standard, similar to academic settings.

Acknowledgments: This work was supported by a Doctoral Student Research Grant from the Graduate Center at the City University of New York (New York, NY, USA).

Conflicts of Interest: The author declares no conflict of interest.

\section{References}

1. Lenhart, A. A Majority of American Teens Report Access to a Computer, Game Console, Smartphone and a Tablet; Report for Pew Research Center Internet Technology: Washington, DC, USA, April 2015. Available online: http:/ / www.pewinternet.org/files/2015/04/PI_TeensandTech_Update2015_0409151.pdf (accessed on 9 March 2016).

2. Smith, A. U.S. Smartphone Use in 2015; Report for Pew Research Center Internet Technology: Washington, DC, USA, April 2015. Available online: http://www.pewinternet.org/2015/04/01/us-smartphone-use-in-2015/ (accessed on 28 November 2016).

3. Horrigan, J.B.; Duggan, M. Home Broadb and 2015; Report for Pew Research Center Internet Technology: Washington, DC, USA, December 2015. Available online: http:/ /www.pewinternet.org/2015/12/22/2015/ Home-Broadband-2015/ (accessed on 12 February 2017).

4. Pew Internet Research. Mobile Fact Sheet. Available online: http://www.pewinternet.org/fact-sheet/ mobile/ (accessed on 12 February 2017).

5. Bárcena, E.; Read, T.; Underwood, J.; Obari, H.; Cojocnean, D.; Koyama, T.; Pareja-Lora, A.; Calle, C.; Pomposo, L.; Talaván, N.; et al. State of the art of language learning design using mobile technology: Sample apps and some critical reflection. In Critical CALL-Proceedings of the 2015 EUROCALL Conference, Padova, Italy, 26-29 August 2015; Helm, F., Bradley, L., Guarda, M., Thouësny, S., Eds.; Research-Publishing.net: Dublin, Ireland, 2015; pp. 36-43.

6. Wu, Q. Designing a smartphone app to teach English (L2) vocabulary. Comput. Educ. 2015, 85, 170-179. [CrossRef]

7. Gass, S.M.; Mackey, A. Input, interaction, and output in second language acquisition. Theories Second Lang. Acquis. Introd. 2006, 19, 3-17.

8. Nielsen. Tops of 2016: Digital. Available online: http://www.nielsen.com/us/en/insights/news/2016/ tops-of-2016-digital.html (accessed on 12 February 2017).

9. Grgurovic, M.; Chapelle, C.A.; Shelley, M.C. A meta-analysis of effectiveness studies on computer technology-supported language learning. ReCALL 2013, 25, 165-198. [CrossRef]

10. Warschauer, M. Computer-mediated collaborative learning: Theory and practice. Mod. Lang. J. 1997, 81, 470-481. [CrossRef]

11. Chapelle, C.A. Multimedia CALL: Lessons to be learned from research on instructed sla. Lang. Learn. Technol. 1998, 2, 22-34.

12. Blake, R. Computer Mediated Communication: A window on L2 Spanish interlanguage. Lang. Learn. Technol. 2000, 4, 120-136.

13. Chapelle, C.A. Second language learning and online communication. In The SAGE Handbook of E-Learning Research; Haythornthwaite, C., Andrews, R., Eds.; SAGE Publications Ltd.: London, UK, 2007; pp. 371-393.

14. Warschauer, M. Comparing face-to-face and electronic discussion in the second language classroom. CALICO J. 1995, 13, 7-26.

15. Jin, S. Using Facebook to promote Korean EFL learners' intercultural competence. Lang. Learn. Technol. 2015, 19, 38-51.

16. Dizon, G. A comparative study of Facebook vs. paper-and-pencil writing to improve L2 writing skills. Comput. Assist. Lang. Learn. 2016, 29, 1-10. [CrossRef]

17. Vandergriff, I. Second-Language Discourse in the Digital World: Linguistic and Social Practices in and beyond the Networked Classroom; John Benjamins Publishing Company: Amsterdam, The Netherlands; Philadelphia, PA, USA, 2016.

18. Mitchell, K. A Social Tool: Why and How ESOL Students Use Facebook. CALICO J. 2012, 29, 471-493. [CrossRef] 
19. Petersen, S.A.; Procter-Legg, E.; Cacchione, A. Creativity and Mobile Language Learning Using LingoBee. Int. J. Mob. Blended Learn. 2013, 5, 34-51. [CrossRef]

20. Godwin-Jones, B. Messaging, Gaming, Peer-to-Peer Sharing: Language Learning Strategies \& Tools for the Millennial Generation. Lang. Learn. Technol. 2005, 9, 17-22.

21. Harrison, M.A.; Gilmore, A.L. U txt WHEN? College students' social contexts of text messaging. Soc. Sci. J. 2012, 49, 513-518. [CrossRef]

22. Jarvis, H.; Krashen, S. Is CALL obsolete? Language acquisition and language learning revisited in a digital age. TESL-EJ 2014, 17, n4.

23. Brown, K.V. Unless you speak English, the internet doesn't care about you. Available online: http: //fusion.kinja.com/unless-you-speak-english-the-internet-doesnt-care-abou-1793854859 (accessed on 14 February 2017).

24. Cingel, D.P.; Sundar, S.S. Texting, techspeak, and tweens: The relationship between text messaging and English grammar skills. New Media Soc. 2012, 14, 1304-1320. [CrossRef]

25. Grace, A.; Kemp, N.; Martin, F.H.; Parrila, R. Undergraduates' attitudes to text messaging language use and intrusions of textisms into formal writing. New Media Soc. 2015, 17, 792-809. [CrossRef]

26. Barker, I. Txts r gr8 but not in exams. Times Educ. Suppl. 2007, 4723, 9.

27. Jones, G.M.; Schieffelin, B.B. Talking text and talking back: 'My BFF Jill' from Boob Tube to YouTube. J. Comput. Mediat. Commun. 2009, 14, 1050-1079. [CrossRef]

28. Tomaszewski, J. Do Texting and "Cyber Slang" Harm Students' Writing Skills? Available online: http:/ / www.educationworld.com/a_admin/arcives/texting_impacts_student-writing.shtml (accessed on 12 February 2017).

29. Tagg, C. A Corpus Linguistics Study of SMS Text Messaging. Ph.D. Thesis, The University of Birmingham, Birmingham, UK, 2009.

30. Tagliamonte, S.A. So sick or so cool? The language of youth on the internet. Lang. Soc. 2016, 45, 1-32. [CrossRef]

31. Drouin, M.; Davis, C. R U txting? Is the use of text speak hurting your literacy? J. Lit. Res. 2009, 41, 46-67. [CrossRef]

32. Kemp, N.; Bushnell, C. Children's text messaging: Abbreviations, input methods and links with literacy. J. Comput. Assist. Learn. 2011, 27, 18-27. [CrossRef]

33. Powell, D.; Dixon, M. Does SMS text messaging help or harm adults' knowledge of standard spelling? J. Comput. Assist. Learn. 2011, 27, 58-66. [CrossRef]

34. Plester, B.; Wood, C.; Joshi, P. Exploring the relationship between children's knowledge of text message abbreviations and school literacy outcomes. Br. J. Dev. Psychol. 2009, 27, 145-161. [CrossRef] [PubMed]

35. Drouin, M. College students' text messaging, use of textese and literacy skills. J. Comput. Assist. Learn. 2011, 27, 67-75. [CrossRef]

36. Rosen, L.D.; Chang, J.; Erwin, L.; Carrier, L.M.; Cheever, N.A. The relationship between "textisms" and formal and informal writing among young adults. Commun. Res. 2010, 37, 420-440. [CrossRef]

37. De Jonge, S.; Kemp, N. Text-message abbreviations and language skills in high school and university students. J. Res. Read. 2012, 35, 49-68. [CrossRef]

38. Waldron, S.; Kemp, N.; Plester, B.; Wood, C. Texting behavior and language skills in children and adults. In The Wiley Handbook of Psychology, Technology, and Society; Rosen, L.D., Cheever, N.A., Carrier, L.R., Eds.; John Wiley \& Sons, Ltd.: Chichester, UK, 2015; pp. 232-249.

39. Wood, C.; Jackson, E.; Hart, L.; Plester, B.; Wilde, L. The effect of text messaging on 9- and 10-year-old children's reading, spelling and phonological processing skills. J. Comput. Assist. Learn. 2011, 27, 28-36. [CrossRef]

40. Wood, C.; Meachem, S.; Bowyer, S.; Jackson, E.; Tarczynski-Bowles, M.L.; Plester, B. A longitudinal study of children's text messaging and literacy development. Br. J. Psychol. 2011, 102, 431-442. [CrossRef] [PubMed]

41. Drouin, M.; Driver, B. Texting, textese and literacy abilities: A naturalistic study. J. Res. Read. 2014, 37, 250-267. [CrossRef]

42. Aziz, S.; Shamim, M.; Aziz, M.F.; Avais, P. The impact of texting/SMS language on academic writing of students-What do we need to panic about? Elixir Linguist. Transl. 2013, 55, 12884-12890.

43. Dansieh, S.A. SMS Texting and Its Potential Impacts on Students' Written Communication Skills. Int. J. Engl. Linguist. 2011, 1, 222. [CrossRef] 
44. Ouellette, G.; Michaud, M. Generation text: Relations among undergraduates' use of text messaging, textese, and language and literacy skills. Can. J. Behav. Sci. 2016, 48, 217-221. [CrossRef]

45. Uzawa, K.; Cumming, A. Writing strategies in japanese as a foreign language: Lowering or keeping up the standards. Can. Mod. Lang. Rev. 1989, 46, 178-194.

46. Lee, S.H. ESL learners' vocabulary use in writing and the effects of explicit vocabulary instruction. System 2003, 31, 537-561. [CrossRef]

47. Muncie, J. Process writing and vocabulary development: Comparing lexical frequency profiles across drafts. System 2002, 30, 225-235. [CrossRef]

48. Lemmouh, Z. The relationship between grades and the lexical richness of student essays. Nord. J. Engl. Stud. 2008, 7, 163-180.

49. Sugawara, M. The effect of productive-use vocabulary exercises on confidence in vocabulary knowledge and receptive and productive vocabulary acquisition. Master's thesis, Bingham Young University, Provo, UT, USA, 1992.

50. Brown, C.; Payne, M.E. Five essential steps of processes in vocabulary learning. Presented at the 28th Annual National TESOL Convention, Baltimore, MD, USA, March 1994.

51. Cummins, J. BICS and CALP: Empirical and theoretical status of the distinction. Encycl. Lang. Educ. 2008, 2, 71-83.

52. August, D.; Carlo, M.; Dressler, C.; Snow, C. The critical role of vocabulary development for English Language Learners. Learn. Disabil. Res. Pract. Wiley-Blackwell 2005, 20, 50-57. [CrossRef]

53. Johansson, V. Lexical diversity and lexical density in speech and writing: A developmental perspective. Work. Pap. Linguist. 2009, 53, 61-79.

54. Read, J. Assessing Vocabulary; Cambridge University Press: Cambridge, UK, 2000.

55. Kobayashi, H.; Rinnert, C. Effects of first language on second language writing: Translation versus Direct Composition. Lang. Learn. 1992, 42, 183-209. [CrossRef]

56. Mackey, A.; Abbuhl, R.; Gass, S.M. Interactionist approach. Routledge Handb. Second Lang. Acquis. 2012, 7-23.

57. Ellis, N. Rules and instances in foreign language learning: Interactions of explicit and implicit knowledge. Eur. J. Cogn. Psychol. 1993, 5, 289-318. [CrossRef]

58. Dörnyei, Z. Motivation in second and foreign language learning. Lang. Teach. 1998, 31, 117-135. [CrossRef]

59. Peirce, B.N. Social identity, investment, and language learning. TESOL Q. 1995, 29, 9-31. [CrossRef]

60. American Community Survey. Census Bureau Reports at Least 350 Languages Spoken in U.S. Homes; Release Number: CB15-185; U.S. Census Bureau: Washington, DC, USA, November 2015. Available online: http: / /www.census.gov/newsroom/press-releases/2015/cb15-185.html (accessed on 22 December 2015).

61. Montes-Alcalá, C. iSwitch: Spanish-English mixing in computer-mediated communication. J. Lang. Contact. 2016, 9, 23-48. [CrossRef]

62. Otheguy, R.; Zentella, A.C. Spanish in New York: Language Contact, Dialectal Leveling, and Structural Continuity; Oxford University Press: Cambridge, UK, 2012.

63. Poplack, S. Sometimes I'll start a sentence in Spanish Y TERMINO EN ESPAÑOL: Toward a typology of code-switching. Linguistics 1980, 18, 581-618. [CrossRef]

64. Klein, E.C.; Martohardjono, G. Understanding the Student with Interrupted Formal Education (SIFE): A Study of SIFE Skills, Needs, and Achievement; Report to the New York City Department of Education, Office of English Language Learners: New York, NY, USA, 2006.

(C) 2017 by the author. Licensee MDPI, Basel, Switzerland. This article is an open access article distributed under the terms and conditions of the Creative Commons Attribution (CC BY) license (http://creativecommons.org/licenses/by/4.0/). 